Published in final edited form as:

Neurosurg Clin N Am. 2019 April ; 30(2): 219-230. doi:10.1016/j.nec.2018.12.005.

\title{
Vagus Nerve Stimulation for the Treatment of Epilepsy
}

\author{
Hernán F.J. González, M.S. ${ }^{1,4}$ [Graduate Student], Aaron Yengo-Kahn, M.D. ${ }^{2}$ [Resident \\ Neurological Surgery], and Dario J. Englot, M.D., Ph.D. 1,2,3,4 [Assistant professor of \\ neurological surgery, Assistant professor of Biomedical Engineering, Surgical Director of \\ Epilepsy] \\ ${ }^{1}$ Departments of Biomedical Engineering, Vanderbilt University Medical Center, Nashville, \\ Tennessee, USA. \\ ${ }^{2}$ Departments of Neurological Surgery, Vanderbilt University Medical Center, Nashville, \\ Tennessee, USA. \\ ${ }^{3}$ Departments of Radiology and Radiological Sciences, Vanderbilt University Medical Center, \\ Nashville, Tennessee, USA. \\ ${ }^{4}$ Vanderbilt University Institute of Imaging Science, Vanderbilt University Medical Center, \\ Nashville, Tennessee, USA.
}

\section{Keywords}

Epilepsy; Seizures; Epilepsy surgery; Neuromodulation; Vagus Nerve Stimulator

\section{Introduction}

\begin{abstract}
About 50 million people worldwide suffer from epilepsy, and about $30-40 \%$ of these persons have seizures that are refractory to treatment with antiepileptic medication. ${ }^{2-4}$ Surgical resection or ablation can result in seizure freedom in well-chosen patients, however, not all persons with epilepsy are candidates for epilepsy surgery. ${ }^{4}$ Furthermore, despite careful selection, some patients may continue to experience seizures postoperatively. ${ }^{5-7}$ In patients whose seizures are inadequately controlled, neuromodulation based interventions should be considered. ${ }^{8}$ Vagus nerve stimulation (VNS) is one of the most common neuromodulation based approaches. The VNS system is a battery powered device that
\end{abstract}

CORRESPONDING AUTHOR: Hernán F.J. González, M.S., $150021^{\text {st }}$ Avenue South, 4340 Village at Vanderbilt, Nashville, Tennessee 37232-8618, hernan.gonzalez@ vanderbilt.edu. AUTHOR CONTACT INFORMATION:

Hernán F.J. González, M.S., $150021^{\text {st }}$ Avenue South, 4340 Village at Vanderbilt, Nashville, Tennessee 37232-8618, hernan.gonzalez@vanderbilt.edu

Dario J. Englot, M.D., Ph.D., $150021^{\text {st }}$ Avenue South, 4340 Village at Vanderbilt, Nashville, Tennessee 37232-8618, englot@gmail.com

Aaron Yengo-Kahn, M.D., $112121^{\text {st }}$ Avenue South, Medical Center North, T4224, Nashville, Tennessee 37232, a.yengo@ vumc.org

Publisher's Disclaimer: This is a PDF file of an unedited manuscript that has been accepted for publication. As a service to our customers we are providing this early version of the manuscript. The manuscript will undergo copyediting, typesetting, and review of the resulting proof before it is published in its final citable form. Please note that during the production process errors may be discovered which could affect the content, and all legal disclaimers that apply to the journal pertain.

DISCLOSURE STATEMENT

The Authors have nothing to disclose. 
resembles a cardiac pacemaker (Figure1). The VNS consists of an implanted pulse generator implanted below the clavicle and lead that is wrapped around the left vagus nerve in the carotid sheath. Although complete seizure freedom with VNS therapy is rare, it may be beneficial in reducing seizure frequency and improving quality of life (QOL) ${ }^{8}$

Several important and early studies of VNS on brain activity were conducted by Bailey and Bremmer in 1938 and by Dell and Olson in 1951. ${ }^{9-11}$ These studies proposed that stimulation of the vagus nerve affected cortical activity by way of nucleus tractus solitarii projections to other brainstem nuclei, such as the locus coeruleus and raphe magnus, which project diffusely to the cortex. ${ }^{9}$ It has been proposed that VNS exhibits antiepileptic therapy by decreasing interictal events and by desynchronizing cortical activity. ${ }^{12-14}$ Zabara additionally showed that anticonvulsant effects of VNS lasted at least four times the duration of stimulation. ${ }^{13,15,16}$ Dr. Jacob Zabara and Terry Reese developed the first generation of the vagus nerve stimulator through their newly incorporated company Cyberonics in 1987 (now LivaNova). In 1988, Dr. William Bell implanted the first VNS, the NeuroCybernetic Prosthesis, at Wake Forest University. ${ }^{9}, 17$ In July 1997, the United States Food and Drug Administration (FDA) approved VNS as adjunctive therapy for adults and adolescents (older than 12 years old) with partial onset seizures that are refractory to antiepileptic medications. More recently, the FDA has expanded VNS approval as an adjunctive treatment in patients 4 years and older with partial onset seizures refractory to medications. ${ }^{18}$ Since its original approval over 20 years ago, more than 100,000 patients have been implanted with VNS. ${ }^{19}$

\section{Short term outcomes of vagus nerve stimulation from randomized controlled trials}

Efficacy of VNS for the treatment of epilepsy has been examined in four blinded, randomized controlled trials (Class I data), which are summarized in table $1 .{ }^{20-24}$ In a 1994 study led by Ben-Menachem et al., 114 patients with partial epilepsy were randomized at multiple centers. ${ }^{20}$ These patients received either high-frequency ("therapeutic") or lowfrequency ("sham") stimulation paradigms. At a three month follow-up, this study reported that high-frequency stimulation reduced seizure frequency by $25 \%$ and low-frequency stimulation reduced seizure frequency by $6 \%$. A responder to VNS therapy is commonly defined as seizure frequency reduction by at least $50 \%$, a definition we will use from this point forward. ${ }^{25}$ In this study, $31 \%$ of patients receiving high-frequency stimulation achieved responder status. ${ }^{20}$

In a subsequent multicenter randomized controlled trial, Handforth et al. randomized 196 patients with partial epilepsy to receive either high-frequency stimulation or sham stimulation. ${ }^{21}$ Patients with high-frequency stimulation achieved $28 \%$ reduced seizure frequency while those with sham stimulation had a 15\% decrease. Overall, $23 \%$ of those receiving therapeutic stimulation (high-frequency) achieved responder status at the three month postoperative follow-up. Amar et al. provided further evidence of VNS efficacy with the publication of a randomized controlled trial of VNS implantation in 17 persons resulting in $57 \%$ of patients achieving responder status. ${ }^{22}$ 
In the first randomized controlled trial for children with intractable epilepsy, Klinkenberg et al. randomized patients with partial $(\mathrm{N}=35)$ or generalized epilepsy $(\mathrm{N}=6)$ to high-output stimulation (maximum $1.75 \mathrm{~mA}$ ) or low-output stimulation $(0.25 \mathrm{~mA}$ ) for 20 weeks, followed by an add-on period of 19 weeks of high-output stimulation for all patients. ${ }^{24}$ At the end of the randomized controlled blinded period, $16 \%$ of patients receiving high stimulation and $21 \%$ of patients receiving low stimulation achieved responder status. After the add-on phase, $26 \%$ of patients experienced at least $50 \%$ reduced seizure frequency. ${ }^{24}$ In summary, blinded randomized controlled trials for both children and adults with intractable epilepsy have demonstrated that $23 \%$ - $57 \%$ of patients typically achieve $50 \%$ seizure reduction with VNS implantation in short term follow-up. ${ }^{20-22,24}$

Additionally, these conclusions are supported by two nonblinded randomized controlled trials (Class II data, Table 1) comparing vNs stimulation parameters. The first, a single center study, was conducted by Scherrmann et al. and included 28 patients, and the second, a multicenter study, was performed by DeGiorgio et al. and included 61 patients. ${ }^{26,27}$ Scherrmann et al. reported median seizure reduction of $30 \%$ and that $45 \%$ of patients achieved responder status. ${ }^{26}$ DeGiorgio et al. reported a median seizure reduction of $26 \%$ and that $29 \%$ of patients achieved responder status. ${ }^{27}$

\section{Long term seizure outcomes for VNS from retrospective and prospective cohort studies}

Long term studies, including 13 prospective observational studies (Class III data, Table 1), have shown progressive increases in response to VNS with increased duration of implant. 1,23,25 These studies included between 16 and 95 patients and follow- up periods of 3 to 64 months. As seen in table 1, results from these studies report a median seizure reduction rate between $17 \%$ - 55\% and responder rates between $21 \%$ - 54\%. To further evaluate VNS response rate over time, one group conducted a review of VNS therapy patient outcome registry data and literature review including 5554 and 2869 patients respectively. ${ }^{1}$ From registry data, $49 \%$ of patients were responders to therapy and $5.1 \%$ of patients were seizure free at zero to four months post-implantation. Subsequently, at $24-48$ months, $63 \%$ of patients were responders with $8.2 \%$ achieving seizure freedom. The authors' literary review yielded similar results (Figure 2), with $40 \%$ of patients being responders at zero to four months (2.6\% seizure free), and $60.1 \%$ of patients responded to therapy at last follow-up ( $8.0 \%$ seizure free). ${ }^{1}$ It is important to note, however, that these studies are not controlled in nature, and therefore may be susceptible to selection bias, and can overestimate long term favorable outcomes, as patients not receiving response may be less likely to continue therapy.

\section{Quality of life (QOL) outcomes in VNS}

The most important predictor for QOL in patients with epilepsy is freedom from seizures. ${ }^{28}$ As discussed above, VNS only leads to seizure freedom in about eight percent of patients. ${ }^{1}$ Therefore, understanding other QOL outcomes in epilepsy patients with VNS has helped providers to better advise patients about this treatment. One study specifically evaluated QOL metrics in 5000 patients using the VNS therapy patient outcome registry. ${ }^{29}$ In general, 
this group reported that use of VNS for medically refractory epilepsy was associated with many QOL improvements. However, these findings were based on data subjectively recorded by treating physicians and are therefore susceptible to bias. Specifically, this study reported that patients experienced improvements in alertness (58\% - 63\%), post-ictal state (55\% - 62\%), cluster seizures ( $48 \%$ - 62\%), mood change (43\% - 49\%), verbal communications ( $38 \%$ - 45\%), school/professional achievements (29\% - 39\%), and memory $(29 \%-38 \%) .{ }^{29}$ Additional benefits include reduced sudden unexpected death in epilepsy (SUDEP) rates over time with VNS therapy. ${ }^{30}$ Improvements in QOL metrics have been seen in both responders and non-responders, and in adults and children. ${ }^{29,31}$ Interestingly, unlike seizure frequency, QOL metrics were not found to improve over time (as seen in figure 3), ${ }^{29}$ which may imply that benefit from VNS is not solely due to effects on seizure frequency, or may reflect study bias.

\section{Factors associated with outcome}

As with resective surgery, optimal patient selection plays a central role in predicting outcomes of VNS implantation, so understanding factors associated with outcome is imperative. ${ }^{1,8,32}$ Currently, VNS is approved as adjunctive therapy in patients four years of age and older with partial onset seizures refractory to medication. ${ }^{18}$ Despite the narrow indications for use, VNS has been implemented for treatment of many types of patients with medically refractory epilepsy. A 2015 study of predictors of seizure freedom found that at 4 - 48 months $8.2 \%$ of implanted patients became seizure free. ${ }^{1}$ Seizure freedom was predicted by age of epilepsy onset $>12$ years of age (odds ratio (OR): 1.89 and $95 \%$ confidence interval (95CI) 1.01-1.82), and by having a generalized seizure type (OR: 1.38 and 95CI: $1.06-1.81$ ). Overall patient response (greater than $50 \%$ seizure frequency reduction) was predicted by having non-lesional epilepsy (OR: 1.38 and 95CI: 1.06-1.81) and about $60 \%$ all of patients were responders at last follow-up. ${ }^{1}$

Studies of patient groups not included in the original FDA approval (greater than 12 years of age with medically intractable partial epilepsy) have shown that VNS may be beneficial in a wide range of patients with medically refractory epilepsy. An example population that merits consideration are patients with posttraumatic epilepsy (PTE). PTE is a common consequence of traumatic brain injury and accounts for about $20 \%$ of symptomatic epilepsy cases. ${ }^{33,34}$ These patients are often resistant to treatment with antiepileptic medications and may be unlikely to have a localizable lesion. ${ }^{35}$ In a retrospective study, summarized in figure 4, patients with PTE who received VNS achieved greater seizure frequency reduction than patients with nontraumatic epilepsy both at three month follow-up (50\% vs $46 \%$ fewer seizures) and 24 month follow-up (73\% vs 57\% fewer seizures). ${ }^{36}$ Furthermore, patients with PTE had an overall responder rate of $78 \%$ at 24 months versus $61 \%$ in the nontraumatic epilepsy group. ${ }^{36}$ Additionally, children $(<18$ years of age) and patients with less than 10 years of seizures have shown better response to VNS than adults or those with duration greater than 10 years respectively. ${ }^{23}$ Another group that has shown favorable outcome with VNS is patients with Lennox-Gastaut syndrome, whose seizure types are typically considered primary generalized. ${ }^{25,30}$ These findings indicate that further study of different patient characteristics may yield insight regarding which patients may have greater probability of experiencing a positive response to VNS therapy. 


\section{Ictal tachycardia}

Modern VNS systems have multiple programming options allowing customization of therapy delivery for individual patients. One common initial programming of VNS stimulation parameters consists of open-loop stimulation cycles of 30 seconds of stimulation every 5 minutes. ${ }^{37}$ Additionally, VNS also allows user-initiated stimulation at or before the time of seizure onset with the VNS Manual Magnet Mode. ${ }^{37}$ With this manual stimulation initiated by patients or caregivers, some patients may experience benefits such as aborted seizures or decreased post-ictal state. ${ }^{30,38}$ However, manual triggering of stimulation may not always be feasible for a variety of reasons, such as lack of premonitory symptoms or seizures in sleep. An automated trigger for stimulation would address some barriers to manual stimulation at time of seizure. Heart rate is an easily measured extracranial biomarker for seizure detection that has been recently implemented into a VNS model.

Ictal tachycardia is defined as increase in heart rate above baseline that is associated with ictal events. ${ }^{39,40}$ In a review of 34 articles, Eggleston et al. reported that about $82 \%$ of patients with epilepsy experience ictal tachycardia. ${ }^{40}$ Furthermore, when examined by seizure type: $64 \%$ of generalized seizures and $71 \%$ of partial onset seizures were associated with significant heart rate changes. ${ }^{40}$ Previous research suggests that propagation of epileptic activity to the right insular cortex may be one mechanism for autonomic nervous system perturbations resulting in ictal heart rate fluctuations. ${ }^{41}$ Using this knowledge of ictal tachycardia, the Model 106 VNS Therapy system (LivaNova) includes an automatic stimulation mode (AutoStim) that stimulates the vagus nerve upon detecting tachycardia. $37,42,43$

The efficacy of the AutoStim mode has been studied in two multisite trials: one in the United States (E-37) and one in Europe (E-36). ${ }^{42,43}$ Both of these studies defined ictal tachycardia as a heart rate of $>100$ beats per minute (bpm) during a seizure, with at least a $55 \%$ increase or 35 bpm increase from baseline heart rate. ${ }^{42,43}$ The E- 37 protocol was a prospective, unblinded United States multisite study of this feature in 20 patients with medically refractory partial onset seizures and history of ictal tachycardia. At 12 months, Fisher and colleagues report that QOL and seizure severity scores may improve with a responder rate of $50 \% .{ }^{42}$ They noted that during an inpatient observation period, about $43 \%$ of all seizures occurred with at least a $20 \%$ increase in heart rate compared to baseline heart rate and that complex partial seizures were most likely to be associated with higher heart rate increases. ${ }^{42}$ During the E-36 trial, responder rate at 12 months was reported as $29.6 \% .{ }^{43}$ Extra stimulations triggered by ictal tachycardia did not significantly affect battery life, with measured duty cycles increasing from $11 \%$ to $16 \%$ with AutoStim activated in the E-37 trial. 42 There are two mechanisms to avoid false positives in the Model 106. First, to avoid false positives due to exercise, AutoStim is triggered by an increase from a baseline heart rate that is continually updated from a moving average. Therefore, while false positive stimulations are possible at the beginning of an exercise session, these should subside once the baseline heart rate is updated to reflect increased heart rate of exercise. Second, a tachycardia detection threshold can be can be customized for each patient as increase from baseline heart rate of $20 \%-70 \% .{ }^{37}$ Additionally, false positive stimulations would not incur any additional risk of adverse events compared to the regularly scheduled stimulations patients receive with 
standard open-loop VNS. In summary, ictal tachycardia triggered VNS is at least as effective as standard open-loop VNS and may help abort or reduce severity of seizures in some patients.

\section{Adverse effects and complications}

Adverse events associated with VNS fall into two categories: (i) those associated with surgical implantation and (ii) those associated with electrical stimulation. ${ }^{15}$ The most common adverse effects of VNS, as summarized by four studies, are shown in table $2 .^{20,21,24,44}$ In a recent large retrospective study of 247 primary VNS implants BenMenachem and colleagues examined adverse effects specific to the surgical implantation. ${ }^{45}$ This group reported a surgical complication rate of $8.6 \%$, with the most common complications being postoperative hematoma in $1.9 \%$, infection in $2.6 \%$, and vocal cord palsy in $1.4 \%$ of cases. ${ }^{45}$ Across the studies in table 2 and others, hoarseness is the most prevalent adverse effect reported from stimulation. ${ }^{23}$ Additionally, asystole or severe bradycardia has been described in very few cases of VNS intraoperatively and postoperatively (0.06 events per 1000 patient years from July 1997 to March 2011). ${ }^{25,46}$ Finally, some recent studies have suggested that there may be an association between VNS and sleep apnea, however, the latest American Academy of Neurology guidelines on VNS state that the clinical importance of this effect is still unclear. ${ }^{30,47}$

\section{Non-invasive vagus nerve stimulation}

Implantable VNS is a safe and efficacious treatment for medically refractory epilepsy. However, newer non-invasive VNS systems (nVNS) posit to offer the advantage of avoiding most common VNS associated adverse events. ${ }^{48}$ The primary advantage of the non-invasive based treatment is avoiding surgery and therefore avoiding implantation associated adverse events such as infection and vocal cord paresis. ${ }^{49}$ Additionally, nVNS claims to limit stimulation related adverse events by allowing greater customization of stimulation paradigm. ${ }^{48}$ NEMOS (Cerbomed, Erlangen, Germany) is an external transcutaneous VNS available in Germany, Austria, Switzerland, and Italy. ${ }^{49}$ NEMOS stimulates the auricular branch of the vagus nerve using an intra-auricular electrode. Patients can control their VNS stimulation during treatment sessions which occur three to four times a day and may each last one to four hours or they may stimulate before a seizure. In a proof of concept trial involving 10 patients with medically refractory epilepsy using one-hour treatments three times a day, five patients reported some seizure frequency reductions, but none achieved $50 \%$ reduced seizure frequency. ${ }^{50} \mathrm{~A}$ second non-invasive VNS device is the gammaCore device (electroCore LC. Basking Ridge, NJ, United States of America), which has been studied for patients with chronic headache and migraine but not in patients with epilepsy. 51-53 The gammaCore device is a handheld portable stimulator with two stainless steel round discs that are placed on the skin to deliver electrical stimulation to the vagus nerve. In summary, the advantages of nVNS are they avoid any adverse events associated with surgery for implantable VNS and with less frequent stimulation may reduce the amount of stimulation associated adverse events. ${ }^{49}$ However, true efficacy of these nVNS devices has yet to be proven for medically refractory epilepsy, therefore implantable VNS currently remain the superior choice for seizure control. 


\section{Future directions for VNS:}

Future directions for usage of VNS therapies are extensive. For the first 20 years of its use, VNS was FDA approved only for patients 12 years and older with medically refractory partial epilepsy. However, recent changes have expanded this approval to patients as young as four years old with medically refractory partial epilepsy. ${ }^{18}$ As we have discussed above, multiple studies have shown efficacy in patients outside of these categories such as patients with generalized types of epilepsy or non-localizable posttraumatic epilepsy, and future approval for these patients may increase the number of people who benefit from VNS. ${ }^{1,25,36}$ Additionally, future VNS systems with closed-loop seizure detection and responsive stimulation may provide additional benefit. ${ }^{38}$ These VNS systems may resemble the responsive neurostimulation system (RNS, Neuropace, Mountain View, CA, United States of America). Like the RNS system a closed-loop VNS may offer not only the benefits of seizure onset induced stimulation, but also may also record and provide objective data on seizure frequency to help clinicians accurately assess response to treatment. ${ }^{54}$

\section{Summary / Discussion:}

Patients with epilepsy are defined as medically refractory when they have failed to achieve seizure control with two or more antiepileptic medications. ${ }^{4}$ These patients should be referred to a comprehensive epilepsy center for surgical evaluation. ${ }^{8}$ However, surgery remains underutilized, and on average, patients who are referred have already suffered from 20 years of poorly controlled seizures. ${ }^{4,55}$ For patients with certain types of epilepsy, resective epilepsy surgery may result in seizure freedom. ${ }^{4}$ Unfortunately, not all patients are candidates for resective surgery. Despite lower rates of seizure freedom, patients who are not candidates for resective surgery should still be offered surgical treatment with neuromodulation techniques, such as VNS therapy. With two to four years of VNS therapy, about $8 \%$ of patients will reach seizure freedom, and about $50-60 \%$ will have at least $50 \%$ reduction in seizure frequency. ${ }^{1}$ VNS has been used for more than twenty years in clinical practice and serves a vital role for patients with epilepsy who are poor surgical candidates, such as those with generalized or non- localizable epilepsy, and individuals who have failed resection. ${ }^{1}$

\section{References:}

1. Englot DJ, Rolston JD, Wright CW, Hassnain KH, Chang EF. Rates and Predictors of Seizure Freedom With Vagus Nerve Stimulation for Intractable Epilepsy. Neurosurgery. 2015;79(3):345353.

2. Behr C, Goltzene MA, Kosmalski G, Hirsch E, Ryvlin P. Epidemiology of epilepsy. Rev Neurol (Paris). 2016;172(1):27-36. [PubMed: 26754036]

3. Engel J What can we do for people with drug-resistant epilepsy? The 2016 Wartenberg Lecture. Neurology. 2016;87(23):2483-2489. [PubMed: 27920283]

4. Wiebe S, Jette N. Pharmacoresistance and the role of surgery in difficult to treat epilepsy. Nat Rev Neurol. 2012;8(12):669-677. [PubMed: 22964510]

5. Englot DJ, Raygor KP, Molinaro AM, et al. Factors associated with failed focal neocortical epilepsy surgery. Neurosurgery. 2014;75(6):648-656. [PubMed: 25181435]

6. Englot DJ, Han SJ, Rolston JD, et al. Epilepsy surgery failure in children: a quantitative and qualitative analysis. Journal of Neurosurgery: Pediatrics. 2014;14(4):386-395. [PubMed: 25127098] 
7. Englot DJ, Lee AT, Tsai C, et al. Seizure types and frequency in patients who "fail" temporal lobectomy for intractable epilepsy. Neurosurgery. 2013;73(5):838-844. [PubMed: 23892416]

8. Englot DJ. A modern epilepsy surgery treatment algorithm: Incorporating traditional and emerging technologies. Epilepsy Behav. 2018;80:68-74. [PubMed: 29414561]

9. Lulic D, Ahmadian A, Baaj AA, Benbadis SR, Vale FL. Vagus nerve stimulation. Neurosurg Focus. 2009;27(3):E5.

10. Bailey P, Bremer F. A sensory cortical representation of the vagus nerve: with a note on the effects of low blood pressure on the cortical electrogram. Journal of Neurophysiology. 1938;1 (5):405412.

11. Dell P, Olson R. Projections thalamiques, corticales et cerebelleuses des afferences viscerales vagales. Comptes rendus des seances de la Societe de biologie et de ses filiales. 1951;145(13-1): 1084-1088. [PubMed: 14896597]

12. Zanchetti A, Wang SC, Moruzzi G. The effect of vagal afferent stimulation on the EEG pattern of the cat. Electroencephalography and clinical neurophysiology. 1952;4(3):357-361. [PubMed: 12989094]

13. Zabara J Peripheral control of hypersynchronous discharge in epilepsy. Electroencephalography and Clinical Neurophysiology. 1985;61 (3):S162.

14. Blum B, Magnes J, Bental E, Liban E. Electroencephalographic studies in cats with experimentally produced hippocampal epilepsy. Clinical Neurophysiology. 1961;13(3):340-353.

15. George MS, Aston-Jones G. Noninvasive techniques for probing neurocircuitry and treating illness: vagus nerve stimulation (VNS), transcranial magnetic stimulation (TMS) and transcranial direct current stimulation (tDCS). Neuropsychopharmacology. 2010;35(1):301-316. [PubMed: 19693003]

16. Zabara J Inhibition of experimental seizures in canines by repetitive vagal stimulation. Epilepsia. 1992;33(6):1005-1012. [PubMed: 1464256]

17. Terry RS, Tarver WB, Zabara J. The implantable neurocybernetic prosthesis system. Pacing and Clinical Electrophysiology. 1991;14(1):86-93. [PubMed: 1705341]

18. Medscape. FDA Okays VNS Therapy for Epilepsy in Children as Young as 4 Years In:6 30, 2017.

19. Browne G Cyberonics Announces 100,000th Patient Implant of VNS Therapy®. In:2012.

20. Ben-Menachem E, Manon-Espaillat R, Ristanovic R, et al. Vagus nerve stimulation for treatment of partial seizures: 1. A controlled study of effect on seizures. Epilepsia. 1994;35(3):616-626. [PubMed: 8026408]

21. Handforth A, DeGiorgio CM, Schachter SC, et al. Vagus nerve stimulation therapy for partial-onset seizures: a randomized active-control trial. Neurology. 1998;51(1):48-55. [PubMed: 9674777]

22. Amar AP, Heck CN, Levy ML, et al. An institutional experience with cervical vagus nerve trunk stimulation for medically refractory epilepsy: rationale, technique, and outcome. Neurosurgery. 1998;43(6):1265-1280. [PubMed: 9848840]

23. Englot DJ, Chang EF, Auguste KI. Vagus nerve stimulation for epilepsy: a metaanalysis of efficacy and predictors of response. J Neurosurg. 2011;115(6):1248- 1255. [PubMed: 21838505]

24. Klinkenberg S, Aalbers MW, Vles JS, et al. Vagus nerve stimulation in children with intractable epilepsy: a randomized controlled trial. Developmental Medicine \& Child Neurology. 2012;54(9): 855-861. [PubMed: 22540141]

25. Englot DJ, Chang EF, Auguste KI. Efficacy of vagus nerve stimulation for epilepsy by patient age, epilepsy duration, and seizure type. Neurosurgery clinics of North America. 2011;22(4):443-448. [PubMed: 21939842]

26. Scherrmann J, Hoppe C, Kral T, Schramm J, Elger CE. Vagus nerve stimulation: clinical experience in a large patient series. Journal of Clinical Neurophysiology. 2001;18(5):408-414. [PubMed: 11709645]

27. DeGiorgio C, Heck C, Bunch S, et al. Vagus nerve stimulation for epilepsy: randomized comparison of three stimulation paradigms. Neurology. 2005;65(2):317-319. [PubMed: 16043810]

28. Taylor RS, Sander JW, Taylor RJ, Baker GA. Predictors of health-related quality of life and costs in adults with epilepsy: a systematic review. Epilepsia. 2011;52(12):2168-2180. [PubMed: 21883177] 
29. Englot DJ, Hassnain KH, Rolston JD, Harward SC, Sinha SR, Haglund MM. Quality-of-life metrics with vagus nerve stimulation for epilepsy from provider survey data. Epilepsy Behav. 2017;66:4-9. [PubMed: 27974275]

30. Morris GL, Gloss D, Buchhalter J, Mack KJ, Nickels K, Harden C. Evidence- based guideline update: Vagus nerve stimulation for the treatment of epilepsy Report of the Guideline Development Subcommittee of the American Academy of Neurology. Neurology. 2013;81(16): 1453-1459. [PubMed: 23986299]

31. Orosz I, McCormick D, Zamponi N, et al. Vagus nerve stimulation for drug- resistant epilepsy: a European long-term study up to 24 months in 347 children. Epilepsia. 2014;55(10):1576-1584. [PubMed: 25231724]

32. Englot DJ, Chang EF. Rates and predictors of seizure freedom in resective epilepsy surgery: an update. Neurosurgical Review. 2014;37(3):389-405. [PubMed: 24497269]

33. Agrawal A, Timothy J, Pandit L, Manju M. Post-traumatic epilepsy: an overview. Clinical neurology and neurosurgery. 2006;108(5):433-439. [PubMed: 16225987]

34. Annegers JF, Coan SP. The risks of epilepsy after traumatic brain injury. Seizure. 2000;9(7):453457. [PubMed: 11034867]

35. Garga N, Lowenstein DH. Posttraumatic epilepsy: a major problem in desperate need of major advances. Epilepsy Currrents. 2006;6(1):1-5.

36. Englot DJ, Rolston JD, Wang DD, Hassnain KH, Gordon CM, Chang EF. Efficacy of vagus nerve stimulation in posttraumatic versus nontraumatic epilepsy. Journal of Neurosurgery. 2012;117(5): 970-977. [PubMed: 22978542]

37. LivaNova-Inc. VNS Therapy Physician's Manual. In. Houstan, Tx 2017.

38. Fisher RS, Eggleston KS, Wright CW. Vagus nerve stimulation magnet activation for seizures: a critical review. Acta Neurol Scand. 2015;131(1):1-8. [PubMed: 25145652]

39. Stefanidou M, Carlson C, Friedman D. The relationship between seizure onset zone and ictal tachycardia: An intracranial EEG study. Clinical Neurophysiology. 2015;126(12):2255-2260. [PubMed: 25817466]

40. Eggleston KS, Olin BD, Fisher RS. Ictal tachycardia: the head-heart connection. Seizure. 2014;23(7):496-505. [PubMed: 24698385]

41. Oppenheimer SM, Gelb A, Girvin JP, Hachinski VC. Cardiovascular effects of human insular cortex stimulation. Neurology. 1992;42(9):1727-1732. [PubMed: 1513461]

42. Fisher RS, Afra P, Macken M, et al. Automatic Vagus Nerve Stimulation Triggered by Ictal Tachycardia: Clinical Outcomes and Device Performance--The U.S. E-37 Trial. Neuromodulation: Technology at the Neural Interface. 2016;19(2):188-195.

43. Boon P, Vonck K, van Rijckevorsel K, et al. A prospective, multicenter study of cardiac-based seizure detection to activate vagus nerve stimulation. Seizure. 2015;32:52-61. [PubMed: 26552564]

44. DeGiorgio CM, Schachter SC, Handforth A, et al. Prospective long-term study of vagus nerve stimulation for the treatment of refractory seizures. Epilepsia. 2000;41 (9):1195-1200. [PubMed: 10999559]

45. Revesz D, Rydenhag B, Ben-Menachem E. Complications and safety of vagus nerve stimulation: 25 years of experience at a single center. Journal of Neurosurgery: Pediatrics. 2016;18(1):97-104. [PubMed: 27015521]

46. Iriarte J, Urrestarazu E, Alegre M, et al. Late-onset periodic asystolia during vagus nerve stimulation. Epilepsia. 2009;50(4):928-932. [PubMed: 19055490]

47. Marzec M, Edwards J, Sagher O, Fromes G, Malow BA. Effects of vagus nerve stimulation on sleep-related breathing in epilepsy patients. Epilepsia. 2003;44(7):930-935. [PubMed: 12823576]

48. Schulze-Bonhage A Brain stimulation as a neuromodulatory epilepsy therapy. Seizure. 2017;44:169-175. [PubMed: 27876408]

49. Ben-Menachem E, Revesz D, Simon BJ, Silberstein S. Surgically implanted and non-invasive vagus nerve stimulation: a review of efficacy, safety and tolerability. European journal of neurology. 2015;22(9):1260-1268. [PubMed: 25614179] 
50. Stefan H, Kreiselmeyer G, Kerling F, et al. Transcutaneous vagus nerve stimulation (t-VNS) in pharmacoresistant epilepsies: a proof of concept trial. Epilepsia. 2012;53(7):e115-118. [PubMed: 22554199]

51. Barbanti P, Grazzi L, Egeo G, Padovan AM, Liebler E, Bussone G. Non-invasive vagus nerve stimulation for acute treatment of high-frequency and chronic migraine: an open-label study. $\mathrm{J}$ Headache Pain. 2015;16:61. [PubMed: 26123825]

52. Goadsby PJ, Grosberg BM, Mauskop A, Cady R, Simmons KA. Effect of noninvasive vagus nerve stimulation on acute migraine: an open-label pilot study. Cephalalgia. 2014;34(12):986-993. [PubMed: 24607501]

53. Nesbitt AD, Marin JCA, Tompkins E, Ruttledge MH, Goadsby PJ. Initial use of a novel noninvasive vagus nerve stimulator for cluster headache treatment. Neurology. 2015;84(12):12491253. [PubMed: 25713002]

54. C H, A P, CE E. Epilepsy: Accuracy of patient seizure counts. Archives of Neurology. 2007;64(11):1595-1599. [PubMed: 17998441]

55. Englot DJ. The persistent under-utilization of epilepsy surgery. Epilepsy Research. 2015;118:68. [PubMed: 26559895]

56. Ben-Menachem E, Hellstrom K, Waldton C, Augustinsson LE. Evaluation of refractory epilepsy treated with vagus nerve stimulation for up to 5 years. Neurology. 1999;52(6):1265-1267. [PubMed: 10214754]

57. Parker APPolkey CE, Binnie CD, Madigan C, Ferrie CD, Robinson RO. Vagal nerve stimulation in epileptic encephalopathies. Pediatrics. 1999;103(4):778-782. [PubMed: 10103302]

58. Labar D, Murphy J, Tecoma E. Vagus nerve stimulation for medication-resistant generalized epilepsy. E04 VNS Study Group. Neurology. 1999;52(7):1510-1512.

59. Chavel SM, Westerveld M, Spencer S. Long-term outcome of vagus nerve stimulation for refractory partial epilepsy. Epilepsy Behav. 2003;4(3):302-309. [PubMed: 12791333]

60. Vonck K, Boon P, D'Have M, Vandekerckhove T, O'Connor S, De Reuck J. Long-term results of vagus nerve stimulation in refractory epilepsy. Seizure. 1999;8(6):328-334. [PubMed: 10512772]

61. Vonck K, Thadani V, Gilbert K, et al. Vagus nerve stimulation for refractory epilepsy: a transatlantic experience. Journal of Clinical Neurophysiology. 2004;21 (4):283-289. [PubMed: 15509917]

62. Majoie HJ, Berfelo MW, Aldenkamp AP, Evers SM, Kessels AG, Renier WO. Vagus nerve stimulation in children with therapy-resistant epilepsy diagnosed as Lennox-Gastaut syndrome: clinical results, neuropsychological effects, and cost- effectiveness. J Clin Neurophysiol. 2001;18(5):419-428. [PubMed: 11709647]

63. Majoie HJ, Berfelo MW, Aldenkamp AP, Renier WO, Kessels AG. Vagus nerve stimulation in patients with catastrophic childhood epilepsy, a 2-year follow-up study. Seizure. 2005;14(1):1018. [PubMed: 15642494]

64. Huf RL, Mamelak A, Kneedy-Cayem K. Vagus nerve stimulation therapy: 2-year prospective open-label study of 40 subjects with refractory epilepsy and low IQ who are living in long-term care facilities. Epilepsy Behavior. 2005;6(3):417-423. [PubMed: 15820352]

65. Kang HC, Hwang YS, Kim DS, Kim HD. Vagus nerve stimulation in pediatric intractable epilepsy: a Korean bicentric study. Acta Neurochir Suppl. 2006;99:93-96. [PubMed: 17370772]

66. Ardesch JJ, Buschman HP, Wagener-Schimmel LJ, van der Aa HE, Hageman G. Vagus nerve stimulation for medically refractory epilepsy: a long-term follow-up study. Seizure. 2007;16(7): 579-585. [PubMed: 17543546]

67. Ryvlin P, Gilliam FG, Nguyen DK, et al. The long-term effect of vagus nerve stimulation on quality of life in patients with pharmacoresistant focal epilepsy: the PuLsE (Open Prospective Randomized Long-term Effectiveness) trial. Epilepsia. 2014;55(6):893-900. [PubMed: 24754318] 


\section{KEY POINTS}

- VNS treatment is an efficacious surgical intervention for patients aged 4 years and older with pharmacoresistant epilepsy who cannot receive or failed resective surgery.

- After more than two years of VNS, about $8 \%$ of patients achieve seizure freedom, and about $50 \%$ will have at least $50 \%$ reduced seizure frequency. ${ }^{1}$

- $\quad$ Serious adverse events with VNS, such as device infection, are rare. 


\section{SYNOPSIS}

VNS was the first neuromodulation device approved for treatment of epilepsy. In more than 20 years of study, VNS has consistently demonstrated efficacy in treating epilepsy. After 2 years, about $50 \%$ of patients will experience at least $50 \%$ reduced seizure frequency. Adverse events with VNS treatment are rare and include surgical adverse events (including infection, vocal cord paresis, etc.) and stimulation side effects (hoarseness, voice change, cough). Future developments in VNS including closed-loop and non-invasive stimulation may reduce side effects or increase efficacy of VNS. 


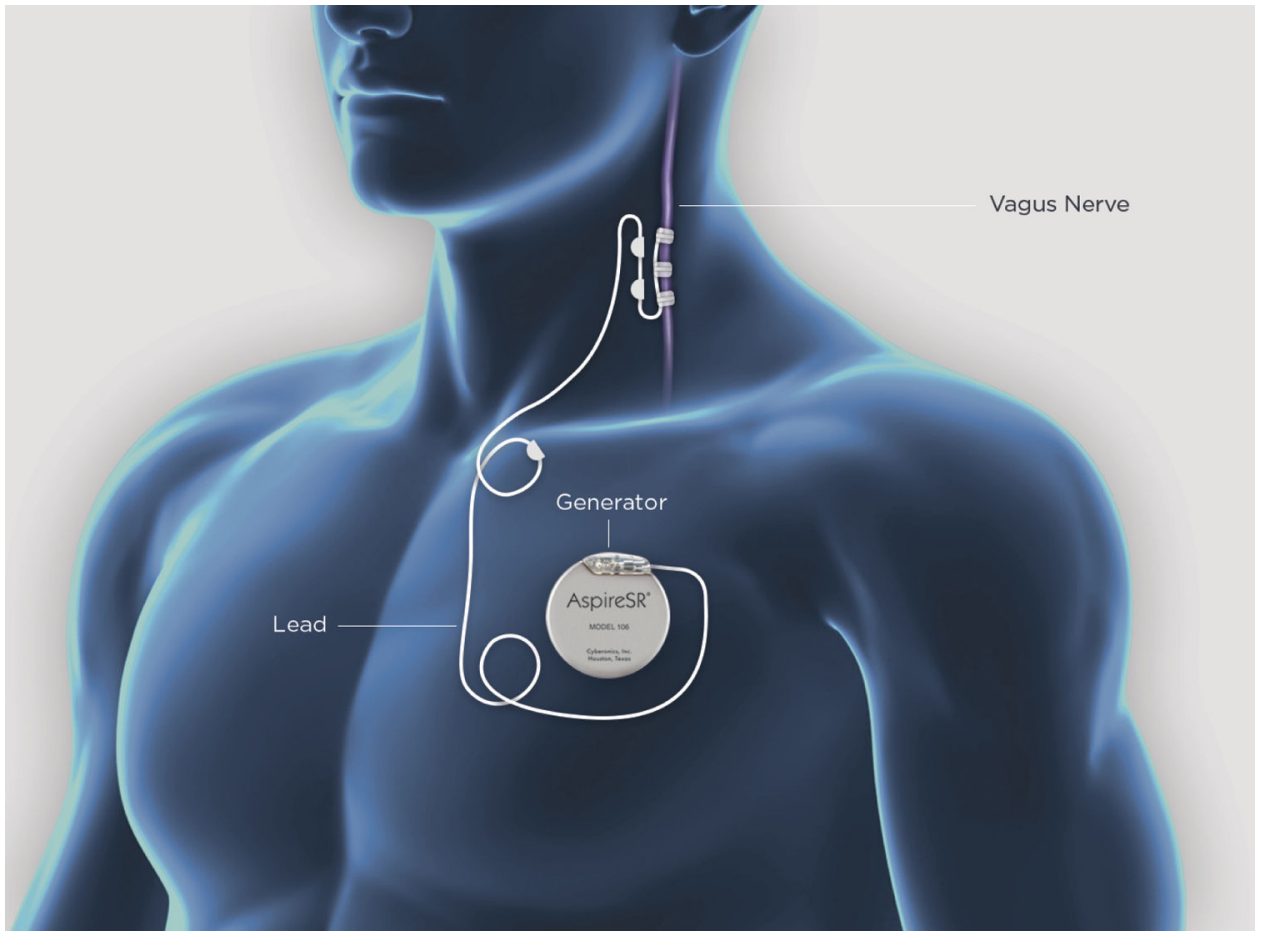

Figure 1. AspireSR $®$ Vagus Nerve Stimulator:

VNS system consists of implanted pulse generator surgically implanted beneath clavicle and lead wrapped around left vagus nerve. (Courtesy of LivaNova, Inc. Houston, TX). 


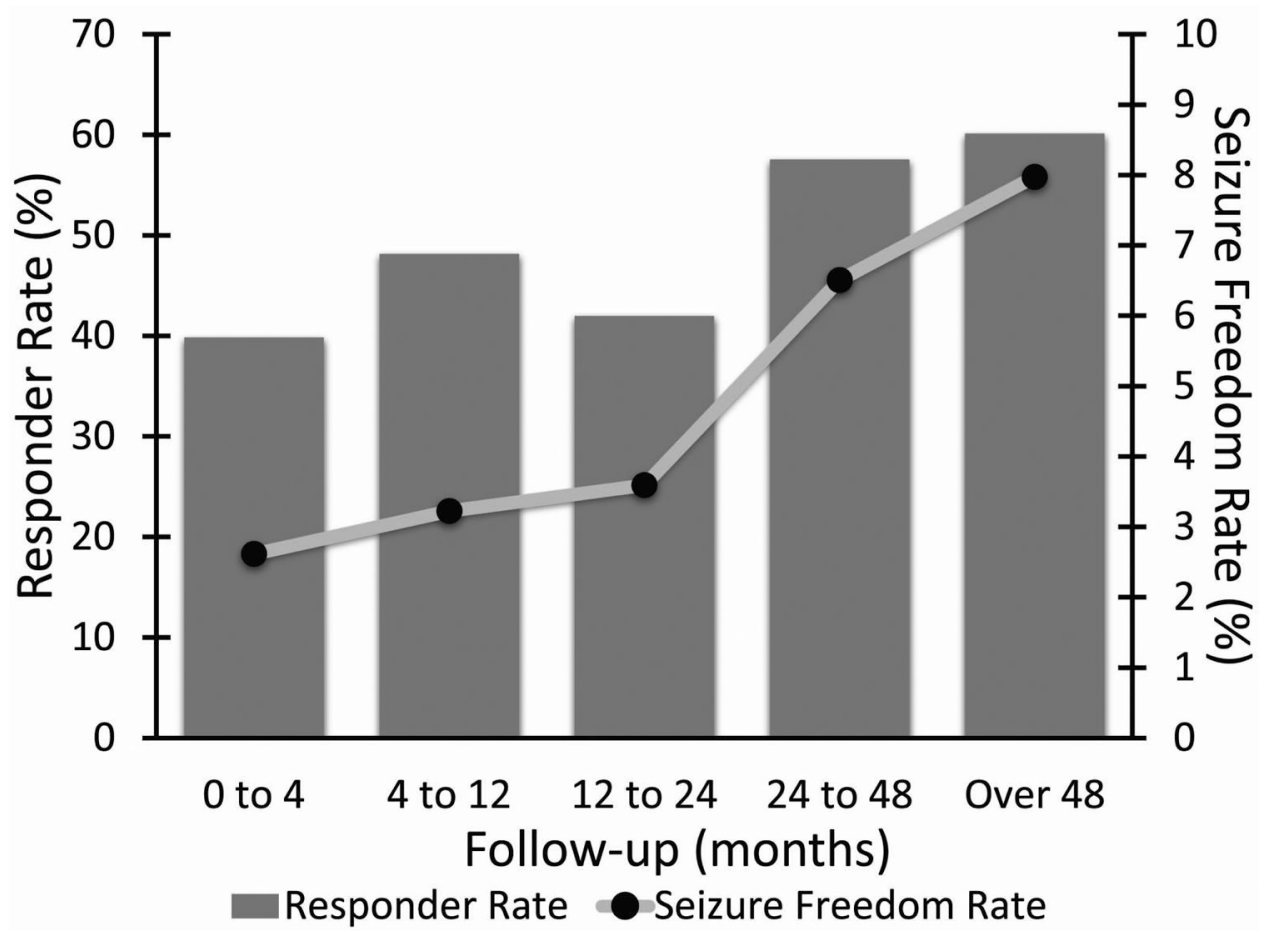

Figure 2. VNS Seizure freedom rate and responder rate from systematic literature review.

This data, from 2869 patients across 78 studies, shows increases in both responder rate and seizure freedom rate over time. At last follow-up $60 \%$ of patients achieved responder status to VNS and $8 \%$ of patients were seizure free. $\mathrm{N}=650,405,1503,876$, and 326 patients at each follow-up period, respectively. VNS, vagus nerve stimulation. (From Englot DJ, Rolston JD, Wright CW, et al. Rates and predictors of seizure freedom with vagus nerve stimulation for intractable epilepsy. Neurosurgery. 2015;79(3):345-353; with permission.) 

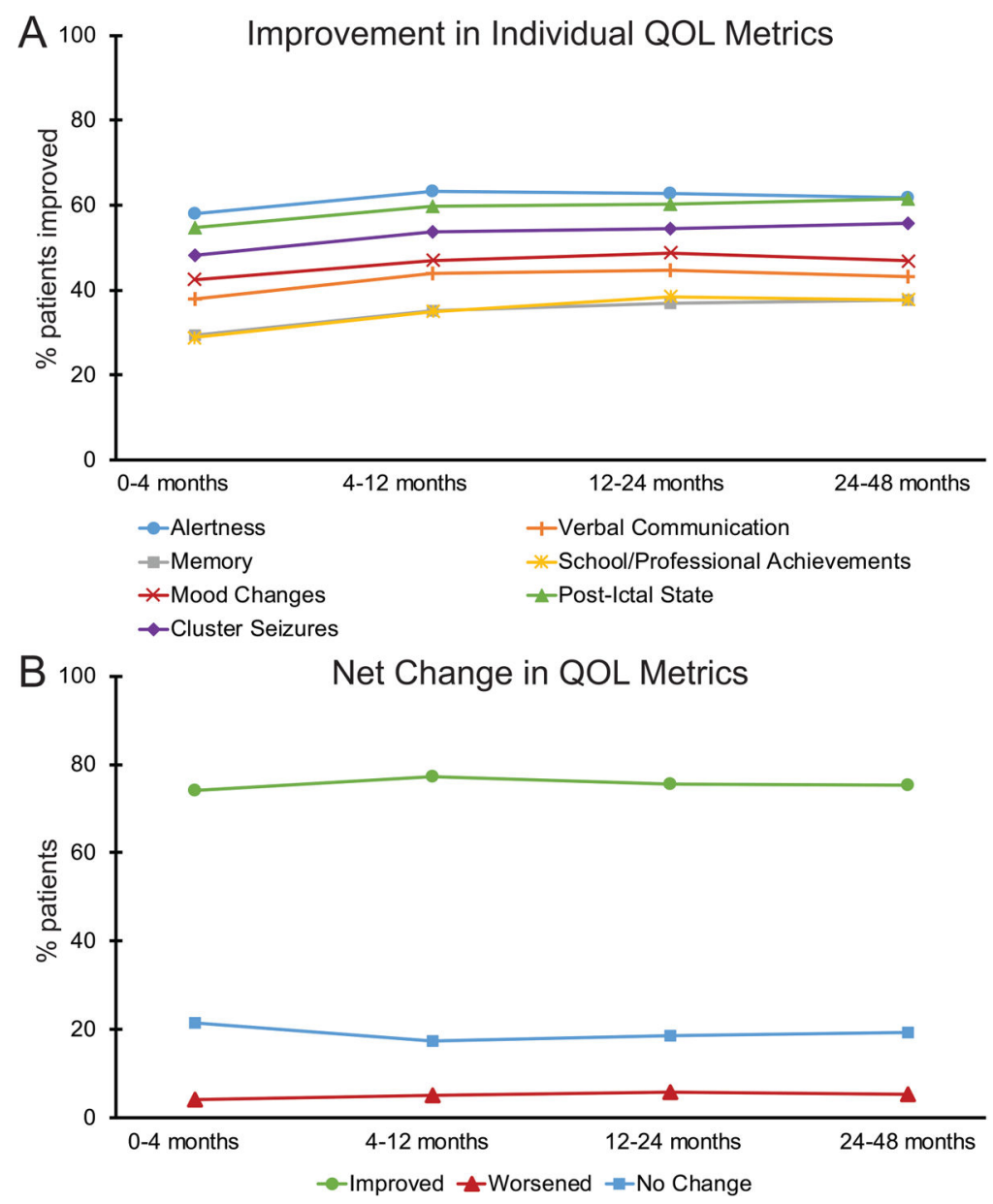

Figure 3. Quality of life metrics for patients with VNS.

(A) When examined individually, multiple metrics of QOL show improvement in patients with VNS as rated subjectively by the treating physician. (B) Overall across all 7 subject QOL metrics there was no trend towards improvement over time with increased time of treatment. For A and B, no significant trends over time were observed $(\mathrm{F}<11, \mathrm{p}>0.05$ per metric, Bonferroni corrected). $\mathrm{N}=4666$ ( 0 - 4 months), 3277 (4 - 12 months), 3182 (12 24 months), and 1194 (24 - 48 months) patients. QOL, quality of life; VNS, vagus nerve stimulation. (From Englot DJ, Hassnain KH, Rolston JD, et al. Quality-of-life metrics with vagus nerve stimulation for epilepsy from provider survey data. Epilepsy Behav. 2017;66:49; with permission.) 
A

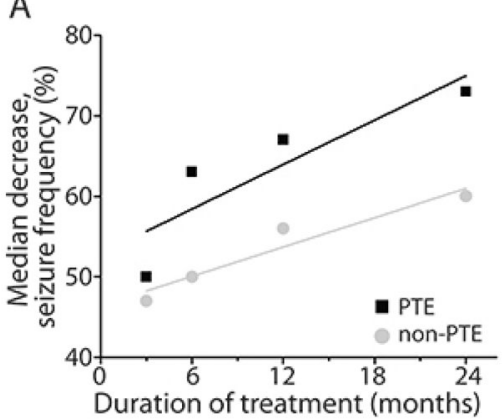

C

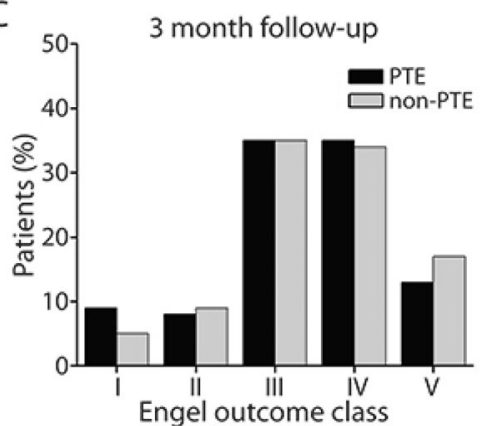

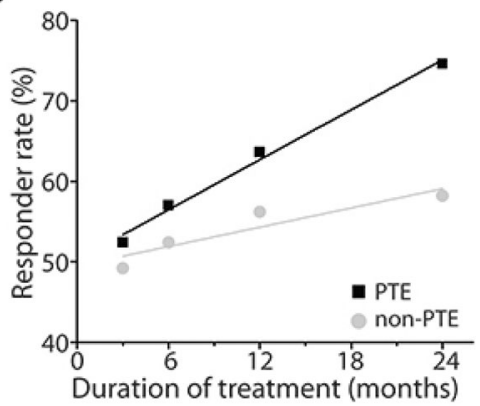

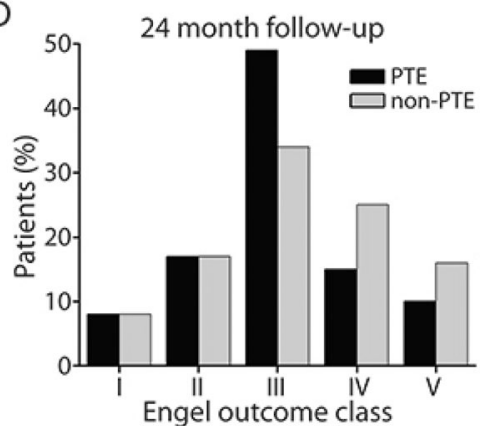

Figure 4. Seizure outcomes after VNS treatment in patients with PTE vs. patients with non postraumatic epilepsy.

The median percent seizure frequency decrease (A) and the responder rates (B) are seen with VNS therapy at 3, 6, 12, and 24 months. Over time, the data shows a trend towards improved seizure outcomes in PTE versus non-PTE patients. When examining Engel outcomes clasess very little difference is found when comparing PTE and non-PTE patients at 3 months after VNS implantation (C). 24 months after VNS (D), patients with PTE exhibit Engel Class III more frequently and Engel Class IV-V less frequently, when compared with non-PTE patients. The number of patients is $254,158,154$, and 71 for those with PTE and 1449, 975, 878, and 364 for those with non-PTE at 3, 6, 12, and 24 months, respectively. (From Englot DJ, Rolston JD, Wang DD, et al. Efficacy of vagus nerve stimulation in posttraumatic versus nontraumatic epilepsy. J Neurosurg. 2012;117(5):970-977; with permission.) 
Table 1:

\section{Class I, II, and III evidence of VNS efficacy in epilepsy treatment}

Adapted from Englot DJ, Chang EF, Auguste KI. Vagus nerve stimulation for epilepsy: a meta-analysis of efficacy and predictors of response. J Neurosurg. 2011;115(6):1248-1255; with permission.

\begin{tabular}{|c|c|c|c|c|c|c|c|}
\hline \multicolumn{8}{|c|}{ Class I evidence: Blinded, randomized controlled trials } \\
\hline$\underline{\text { Study }}$ & $\underline{\mathrm{N}}$ & $\underline{\text { Seizure type }}$ & Comparison & Follow-up & No.centers & $\begin{array}{l}\frac{\text { Mean \% }}{\text { seizure }} \\
\text { reduction }\end{array}$ & $\frac{\frac{\% \text { patients }}{\text { with }>50 \%}}{\text { reduction }}{ }^{*}$ \\
\hline Ben-Menachem, $1994^{20}$ & 114 & partial & high vs. low stim. & 3 months & multi & $\begin{array}{l}25 \text { (high) vs. } \\
6 \text { (low) }\end{array}$ & 31 \\
\hline Handforth, $1998^{21}$ & 196 & partial & high vs. low stim. & 3 months & multi & $\begin{array}{l}28 \text { (high) vs. } \\
15 \text { (low) }\end{array}$ & 23 \\
\hline Amar, $1998^{22}$ & 17 & partial & high vs. low stim. & 3 months & single & $\begin{array}{l}71 \text { (high) vs. } \\
6 \text { (low) }\end{array}$ & 57 \\
\hline Klinkenberg, $2012^{24}$ & 41 & mixed & high vs. low stim. & 3 months & single & $\begin{array}{l}16 \text { (high) vs. } \\
21 \text { (low) }\end{array}$ & $26^{* *}$ \\
\hline \multicolumn{8}{|c|}{ Class II evidence: Non-blinded, randomized controlled trials } \\
\hline$\underline{\text { Study }}$ & $\underline{\mathrm{N}}$ & $\underline{\text { Seizure type }}$ & $\underline{\text { Comparison }}$ & Follow-up & $\underline{\text { No. centers }}$ & $\frac{\text { Median } \%}{\text { seizure }}$ & $\frac{\frac{\% \text { patients }}{\text { with }>50 \%}}{\text { reduction }}$ \\
\hline Scherrmann, $2001^{26}$ & 28 & mixed & 2 stim. paradigms & NR & single & 30 (overall) & 45 \\
\hline DeGiorgio, $2005^{27}$ & 61 & partial & 3 stim. paradigms & 3 months & multi & 26 (overall) & 29 \\
\hline \multicolumn{8}{|c|}{ Class III evidence: Prospective observational studies (>10 patients) } \\
\hline$\underline{\text { Study }}$ & $\underline{\mathrm{N}}$ & $\underline{\text { Seizure type }}$ & $\underline{\text { Notes }}$ & Follow-up & $\underline{\text { No. centers }}$ & $\frac{\underline{\text { Mean or }}}{\frac{\text { median \% }}{\text { seizure }}}$ & $\frac{\frac{\% \text { patients }}{\text { with }>50 \%}}{\text { reduction }}$ \\
\hline Ben-Manachem, $1999^{56}$ & 64 & mixed & & $\begin{array}{l}3 \text { to } 64 \\
\text { months }\end{array}$ & single & NR & 45 \\
\hline Parker, $1999^{57}$ & 15 & mixed & children with encephalopathy & 1 year & single & 17 & 27 \\
\hline Labar, $1999^{58}$ & 24 & gen & & 3 months & single & 46 & 46 \\
\hline DeGiorgio, $2000^{44}$ & 195 & mixed & & 12 months & multi & 45 & 35 \\
\hline Chavel, $2003^{59}$ & 29 & partial & & 1 to 2 years & single & 53 & $\begin{array}{l}54(\text { at } 1 \\
\text { year) }\end{array}$ \\
\hline Vonck, $1999 \& 2004^{60,61}$ & 118 & mixed & & $>6$ months & multi & 55 & 50 \\
\hline $\begin{array}{l}\text { Majoie, } 2001 \& \\
2005^{62,63}\end{array}$ & 19 & mixed & children with encephalopathy & 2 years & single & 20.6 & 21 \\
\hline Huf, $2005^{64}$ & 40 & NR & low IQ adults & 2 years & single & 26 & 28 \\
\hline Kang, $2006^{65}$ & 16 & mixed & children & $>1$ year & multi & 50 & 50 \\
\hline Ardesch, $2007^{66}$ & 19 & partial & & $>2$ years & single & $\begin{array}{l}25(\text { at } 2 \\
\text { years) }\end{array}$ & $\begin{array}{l}33(\text { at } 2 \\
\text { years) }\end{array}$ \\
\hline Ryvlin $2014^{67}$ & 112 & partial & VNS+BMP vs. BMP & 2 years & multi & 23 (at 1 year) & $\begin{array}{c}32(\text { at } 1 \\
\text { year) }\end{array}$ \\
\hline Fisher $2016^{42}$ & 20 & mixed & AutoStim trial & 1 year & multi & 47.3 & 50 \\
\hline Boon $2015^{43}$ & 31 & mixed & AutoStim trial & 1 year & multi & NR & 29.6 \\
\hline
\end{tabular}


Table 2:

Incidence (\%) of adverse effects of VNS for epilepsy

Adapted from Englot DJ, Chang EF, Auguste KI. Vagus nerve stimulation for epilepsy: a meta-analysis of efficacy and preictors of response. J Neurosurg. 2011;115(6):1248-1255; with permission.

\begin{tabular}{lllll}
\hline no. patients follow-up & $\begin{array}{l}\text { Ben-Menachem, 199420 } \\
\mathbf{1 1 4} \text { months }\end{array}$ & $\begin{array}{l}\text { Handforth, 199821 } \\
\text { months }\end{array}$ & $\begin{array}{l}\text { DeGiorgio, 2000 } \\
\text { year }\end{array}$ & $\begin{array}{l}\text { Klinkenberg 2012 } \\
\text { months }\end{array}$ \\
\hline Hoarseness & 37 & 62 & 55 & 19.5 \\
Cough & 7 & 21 & 15 & 7.3 \\
Paresthesia & 6 & 25 & 15 & 4.8 \\
Pain & 6 & 17 & 15 & 7.3 \\
Dyspnea & 6 & 16 & 13 & $\mathrm{NR}$ \\
Headache & 2 & 20 & 16 & 2.4 \\
Infection & $\mathrm{NR}$ & 4 & 6 & 4.8 \\
\hline
\end{tabular}

$\mathrm{NR}=$ not reported 